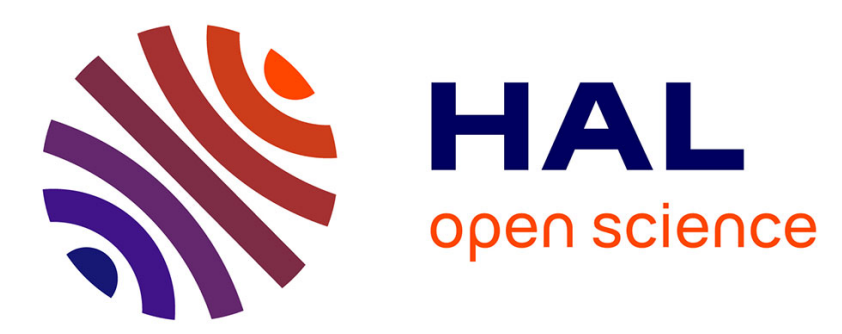

\title{
Measuring Power and Satisfaction in Societies with Opinion Leaders: Properties of the Qualified Majority Case
}

René van den Brink, Agnieszka Rusinowska, Frank Steffen

\section{To cite this version:}

René van den Brink, Agnieszka Rusinowska, Frank Steffen. Measuring Power and Satisfaction in Societies with Opinion Leaders: Properties of the Qualified Majority Case. 2009. halshs-00371813

\section{HAL Id: halshs-00371813 \\ https://shs.hal.science/halshs-00371813}

Submitted on 30 Mar 2009

HAL is a multi-disciplinary open access archive for the deposit and dissemination of scientific research documents, whether they are published or not. The documents may come from teaching and research institutions in France or abroad, or from public or private research centers.
L'archive ouverte pluridisciplinaire HAL, est destinée au dépôt et à la diffusion de documents scientifiques de niveau recherche, publiés ou non, émanant des établissements d'enseignement et de recherche français ou étrangers, des laboratoires publics ou privés. 


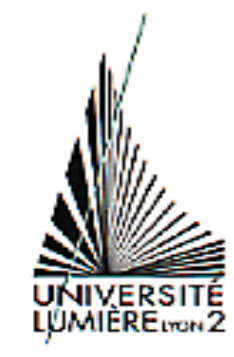

DOCUMENTS DE TRAVAIL - WORKING PAPERS

W.P. 09-01

Measuring Power and Satisfaction in Societies with

Opinion Leaders: Properties of the Qualified

Majority Case

René van der Brink, Agnieszka Rusinowska, Frank Steffen

Janvier 2009

GATE Groupe d'Analyse et de Théorie Économique

UMR 5824 du CNRS

93 chemin des Mouilles - 69130 Écully - France

B.P. $167-69131$ Écully Cedex

Tél. +33 (0)4 72866060 - Fax +33 (0)4 72866090

Messagerie électronique gate@gate.cnrs.fr

Serveur Web : www.gate.cnrs.fr 


\title{
Measuring Power and Satisfaction in Societies with Opinion Leaders: Properties of the Qualified Majority Case
}

\author{
RENE VAN DEN BRINK ${ }^{1}$, AGNIESZKA RUSINOWSKA ${ }^{2}$, and FRANK STEFFEN ${ }^{3}$ \\ 1 Department of Econometrics and Tinbergen Institute, Free University \\ De Boelelaan 1105, 1081 HV Amsterdam, The Netherlands \\ jrbrink@feweb.vu.nl \\ ${ }^{2}$ GATE, CNRS UMR 5824 - Université Lumière Lyon 2 - Ecole Normale Supérieure LSH \\ 93, Chemin des Mouilles - B.P.167, 69131 Ecully Cedex, France \\ rusinowska@gate.cnrs.fr \\ 3 The University of Liverpool Management School (ULMS) \\ Chatham Street, Liverpool L69 7ZH, U.K \\ steffen2@liverpool.ac.uk
}

\begin{abstract}
A well known and established model in communication policy in sociology and marketing is that of opinion leadership. It is based on the idea of a two-step flow of communication. Opinion leaders are actors in a society who are able to affect the behavior of other members of the society called followers. Hence, opinion leaders might have a considerable impact on the behavior of markets and other social agglomerations being made up of individual actors choosing among a number of alternatives. For marketing purposes it appears to be interesting to investigate the effect of different opinion leader-follower structures in markets or any other collective decision-making situations in a society.

We study a two-action model in which the members of a society are to choose one action, for instance, to buy or not to buy a certain joint product, or to vote yes or no on a specific proposal. Each of the actors has an inclination to choose one of the actions. By definition opinion leaders have some power over other actors, their followers, and they exercise this power by influencing the behavior of their followers, i.e. their choice of action. After all actors have chosen their actions, a decisionmaking mechanism determines the collective choice resulting out of the individual choices. The structure of the relations between the actors can be represented by a bipartite digraph. We analyze such digraphs investigating satisfaction and power distributions within societies with and without the opinion leaders. Moreover, we study common properties of the satisfaction and power measures and illustrate our findings and some marketing implications for a society with five members.
\end{abstract}

JEL Classification: C7, D7

Keywords: Bipartite digraph, influence, inclination, collective choice, opinion leader, follower, satisfaction, power

\section{Introduction}

The concept of opinion leadership received considerable attention in sociology and marketing. It rose out of the theory of two-step flow of communication introduced by the 'Lazarsfeld group' (see e.g. Katz and Lazarsfeld, 1955, and Lazarsfeld et al., 1968, [27, 29]). In its most rudimentary form it claims that 'ideas often flow from radio and print to the opinion leaders and from them to the less active sections of the population' (Lazarsfeld et al., 1968, [29]). For instance, Lazarsfeld et al. (1968, [29]) investigated the influence of the mass communication on the 1940 presidential election campaign in the US. They found that the voters' choices were more influenced by actors which they called opinion 
leaders than by mass communication and concluded that the communication process is not a one- but a two-step process. According to this model information distributed by mass media first reaches the so-called opinion leaders. These are actors who are specified as highly self-confident with strong opinions. In Lazarsfeld et al. they act as intermediaries between the mass media and the recipients. In general, the latter actors are called followers. They feel attracted by the opinion leaders holding them in high esteem and are prepared to accept their opinion for their own behavior. Hence, a major characteristic of opinion leaders is their exercised power over their followers. After critiques of the model by the 'Lazarsfeld group' (see e.g. Bostian, 1970, [6]), Troldahl (1966, [38]) introduced a modified version of their model called two cycle flow of communication saying that the two-step flow hypothesis seems to be more adequate as a description of the flow of influence on beliefs and behavior than as a description of the information flow. Troldahl distinguishes then between the flow of information and the influence (exercised by opinion leaders). This corresponded to other results in the field (see e.g. Deutschmann and Danielson, 1960, [11]). The literature on opinion leadership since then has provided a strong body of knowledge of how and why opinion leaders influence followers choices (see Hoyer and Stockburger-Sauer, 2007, [25]).

Opinion leaders form an attractive group for marketing activities in business and politics (see e.g. Hoyer and Stockburger-Sauer, 2007, [25]) as the existence (or non-existence) of opinion leaders in a society and their relations to their followers may have a considerable impact on the behavior of markets (such as consumer or financial markets), and other social agglomerations being made up of individual actors choosing among a number of alternatives (open to them at a given time). For marketing purposes it appears to be interesting to investigate the effect of different opinion leader-follower structures in markets or other collective decision-making situations in a society. This includes questions such as whether it would be worthwhile to establish a new opinion leader in a society or whether a change in the existing opinion leader-follower relationships can be expected to make a difference to the society. However, to our best knowledge there exists no study which addresses this issue on bare theoretical grounds. In this paper we lay the foundation to fill out this lacunae by introducing a power and satisfaction measure for societies with opinion leaders ${ }^{1}$. The former informs us about the power distribution among the members of the society with respect to their ability to affect the state of the society concerning a specific outcome, while the latter tells us to which degree members of the society can be expected to end up with an outcome that they like. We study common properties of both measures and illustrate our findings and some marketing implications for a society consisting out of five members.

For our analysis we consider the example of binary choice as it can also be found in Sinha and Raghavendra (2006, [34]) who study the effect of opinion leaders on market outcomes. It is assumed that an actor can choose among two alternatives. For instance, this can be a market in which the actors have to decide whether they should buy or not buy a joint product, or a voting situation in which the members of the society have to choose to vote either yes or no on a specific proposal. Note, that from now onwards we will only refer to a voting situation. However, all results presented in our paper also

\footnotetext{
${ }^{1}$ Note that this research is in some respects also related to work on opinion leaders and the Condorcet Jury Theorem (see, e.g. Estlund, 1994, [13]), threshold models of collective behavior (see, e.g. Granovetter, 1978, and Granovetter and Soong, 1986, [21,22]) and, in more general terms to the literature on network externalities.
} 
apply to markets. It is assumed that each of the actors has an inclination to choose one of the actions. By the inclination of an actor we mean an action that this actor would choose being 'on its own', that is, if no influence between the actors takes place. We assume that there might exist opinion leaders, who have some power over their followers and exercise this power by influencing the behavior of their followers, i.e. their choice of action. As a result of this influence, the ability of the follower to determine the outcome of the collective choice, i.e. its power to do something (with respect to the outcome of the collective choice) might be affected. The benchmark case is a situation without any opinion leader. For our decision-making mechanism we assume that the actors in the society have to decide whether they would like to remain with the status quo in their society or whether a proposal leading to a new state of the society should be adopted. We let the latter correspond to choosing the yes-action, and former correspond to the no-action. We presuppose that the proposal is exogenous and in line with the inherent idea of opinion leadership that the inclinations of the opinion leaders are becoming public information prior to the real decision via informal discussions of the proposal. Only after these discussions actors will (secretly) choose their action, i.e. decide whether they would like to remain with the status quo or whether they would like to see the proposal being adopted. This implies that we consider a simultaneous decision-making situation. In our model each follower is assumed to follow a certain qualified majority (more than half) of its opinion leaders if these have the same inclination.

In the literature we can find several measures being introduced for analyzing collective decision-making situations with a possible influence between the actors. For instance, some measures for arbitrary digraphs have been studied in van den Brink and Borm (2002, [9]) and van den Brink and Gilles (2000, [10]). Since in the present paper we consider a opinion leader-follower structure which can be represented by a bipartite digraph, our model is related to the studies done in $[9,10]$. Coming from a slightly different direction are the works presented in the voting power literature on power indices. One of the traditional indices is the Rae index (Rae, 1969, [32]) which measures the success of an actor in a voting situation. An actor is said to have been successful if its vote coincides with the voting outcome. Such a successful actor can be additionally powerful or decisive. Decisiveness of an actor is related to other well known power indices, i.e., the absolute Banzhaf index (Banzhaf, 1965, [1], see also Dubey and Shapley, 1979, and Owen, 1975, $[12,31]$ ), and the Shapley-Shubik index (Shapley and Shubik, 1954, [33]). They ascribe power to an actor, i.e. they state that the actor is decisive, if its vote coincides with the voting outcome, but this outcome would have been different if the voter changed its vote. While the absolute Banzhaf index is a probabilistic measure of decisiveness under uniform probability distribution over all vote configurations, the Shapley-Shubik index can be seen as a probabilistic measure of decisiveness, but for a different probability distribution (for a probabilistic approach to power indices, see, e.g. Laruelle and Valenciano, 2005, and Straffin, 1977, 1978, [28, 35,36]). As we are also concerned with measuring power and satisfaction distributions, our research is also related to the work on power indices. In the present paper we analyze satisfaction and power in a digraph by the number of times the collective choice is the same as the inclination of an actor. Power of an actor in a bipartite digraph is measured by the number of times the actor has a swing, where by a swing we mean that an actor by changing its inclination, given the inclinations of the others, enforces a change in the collective choice. 
The paper is structured as follows. In Section 2 we describe the model, and in Section 3 we define the measures of power and satisfaction of actors. In Section 4, first the axioms are presented, and then we prove that the satisfaction and power measures satisfy the given axioms. In Section 5, we illustrate the introduced measures and the properties of the measures in question by a society represented by five-actors digraphs. In Section 6, we draw some conclusions, discuss some possible extensions of the model and future research agenda. Proofs are presented in the Appendix.

\section{The model}

We consider the following model. There is a specific proposal on which $n$ actors can decide upon either by choosing the yes- or no-action. Let $N=\{1, \ldots, n\}$ denote the set of all actors forming the society, and let 1 and 0 stand for the choice of the yes and no-action, respectively. Each actor is assumed to have an inclination to choose either the yes- or noaction. An inclination vector $I=\left(I_{1}, \ldots, I_{n}\right) \in\{1,0\}^{n}$ is a vector which $k^{\text {th }}$ component, $I_{k}$, is 1 if actor $k$ has the inclination to choose the yes-action, and 0 if it is inclined to choose the no-action. It is assumed that some actors may have power over others which they exercise prior to collective choice of this specific proposal, i.e. they influence the decisions of the other actors by making use of their power over them. As mentioned above we refer to the actors which have this influence as opinion leaders, and to the actors which are prepared choose an action according to the inclination of their opinion leaders as followers. Actors that are neither opinion leaders nor followers are called independent actors. We assume simultaneous voting, where the inclinations of the opinion leaders are revealed during informal preliminary discussions. During such preliminary discussions each follower makes up its mind which decision it will take. Some actors may also change their inclinations during the preliminary discussions, but we assume that when choosing their action and after that they do not alter their inclinations. Based on the choice of action of all actors, a collective choice whether the proposal will be accepted or rejected is resulting out of a decision-making mechanism being described below.

The structure of such 'opinion leader-follower' relations is represented by a bipartite directed graph (or bipartite digraph) $(N, D)$ with set of nodes $N$ representing the actors and $D \subset N \times N$ a binary relation on $N$. Since we take the set of actors $N$ fixed, we represent a digraph $(N, D)$ just by its binary relation $D$. Let $S_{D}(k)$ and $P_{D}(k)$ denote the set of successors and predecessors of actor $k$ in digraph $D$, respectively, i.e., for each $k \in N$,

$$
\begin{aligned}
& S_{D}(k)=\{j \in N \mid(k, j) \in D\} \\
& P_{D}(k)=\{j \in N \mid(j, k) \in D\} .
\end{aligned}
$$

As we assume that each actor is either an opinion leader, follower or independent actor, we consider digraphs $D$ such that

$$
\left|S_{D}(k)\right| \cdot\left|P_{D}(k)\right|=0 \text { for each } k \in N
$$

where $|X|$ denotes the cardinality of set $X$. Let $O L(D), F O L(D)$, and $I N D(D)$ denote the sets of all opinion leaders, followers, and independent actors in digraph $D$, respectively, i.e.

$$
O L(D)=\left\{k \in N \mid S_{D}(k) \neq \emptyset\right\}
$$




$$
\begin{aligned}
& F O L(D)=\left\{k \in N \mid P_{D}(k) \neq \emptyset\right\} \\
& I N D=N \backslash(O L(D) \cup F O L(D)) .
\end{aligned}
$$

Therefore, by assumption (1) we have that

$$
O L(D) \cap F O L(D)=\emptyset
$$

and thus the sets $O L(D), F O L(D)$ and $I N D(D)$ form a partition of the set $N$. We denote the collection of all bipartite digraphs on $N$, represented by their binary relation, by $\mathcal{D}^{N}$.

We refer to a pair $(I, D)$ with $I \in\{0,1\}^{n}$ and $D$ a bipartite graph as described above as an opinion leader-follower collective choice situation. After preliminary discussions, all actors simultaneously choose their actions. We assume that the actors in $O L(D) \cup I N D(D)$ make their choice according to their inclinations. If a follower has just one opinion leader, it will choose according to the inclination of its opinion leader. If the follower has more than one opinion leader, then we assume that it will follow a qualified majority of its opinion leaders. In particular, it will follow its opinion leaders if they all have the same inclination.

Let $V=V(I, D) \in\{0,1\}^{n}$ denote the choice vector, that is, a vector which $k^{t h}$ component, $V_{k}$, is 1 if actor $k$ has chosen the yes-action, and 0 if it has chosen the noaction. We assume that for every follower it is specified what fraction (more than half) of its predecessors it will follow. Assuming this fraction to be uniform over the actors, there exists $q \in\left[\frac{1}{2}, 1\right)$, and the choice vector $V=V(I, D) \in\{0,1\}^{n}$ is recursively given by:

$$
V_{k}=I_{k} \text { if } k \in O L(D) \cup I N D(D),
$$

and for $k \in F O L(D)$ :

$$
V_{k}= \begin{cases}x & \text { if }\left|\left\{j \in P_{D}(k) \mid I_{k}=x\right\}\right|>\left[q \cdot\left|P_{D}(j)\right|\right] \\ I_{k} & \text { otherwise }\end{cases}
$$

where $[x]$ denotes the largest integer not greater than $x$. According to $(2)$, given $(I, D)$, if more than the fraction $q$ of the opinion leaders of follower $k$ has the same inclination, then $k$ will follow these opinion leaders, otherwise it will decide according to its own inclination. In particular, if $q=\frac{1}{2}$, and half of the opinion leaders of $k$ are inclined to choose the yes-action and half to choose the no-action, the follower $k$ will follow its own inclination. For sufficiently large $q$, actor $k$ follows its opinion leaders only if they are all unanimous in their inclinations.

After all actors have chosen their actions, a collective choice is resulting according to the decision-making mechanism in use. The decision-making mechanism is given by the collective decision function $C:\{0,1\}^{n} \times \mathcal{D}^{N} \rightarrow 2^{\{0,1\}}$ which assigns an outcome to every pair $(I, D) \in\{0,1\}^{n} \times \mathcal{D}^{N}$. We assume the collective decision function $C$ to be:

- neutral, i.e., $C(I, D)=1$ if and only if $C\left(I^{c}, D\right)=0$, where $I_{k}^{c}=1$ if and only if $I_{k}=0$

- anonymous, i.e., for every permutation $\pi: N \rightarrow N, C(I, D)=C(\pi(I), \pi(D))$ with $\pi(I)_{k}=I_{\pi(k)}$ and $(\pi(k), \pi(j)) \in \pi(D)$ if and only if $(k, j) \in D$. 
Let for $x \in\{0,1\}$ and $V \in\{0,1\}^{n}$

$$
n_{x}(V)=\left|\left\{k \in N \mid V_{k}=x\right\}\right|
$$

be the number of actors choosing action $x$. We define the collective decision function by simple majority voting, i.e., for each $(I, D)$ :

$$
C(I, D)=\left\{\begin{array}{cl}
1 & \text { if } n_{1}(V(I, D))>n_{0}(V(I, D)) \\
0 & \text { if } n_{0}(V(I, D))>n_{1}(V(I, D)) \\
x \in\{0,1\} & \text { if } n_{1}(V(I, D))=n_{0}(V(I, D)),
\end{array}\right.
$$

where in the last case, which may occur for an even number of actors, we assign the outcomes 1 or 0 such that $C(I, D) \neq C\left(I^{c}, D\right)$ and the decision function $C$ is neutral.

\section{Measuring satisfaction and power}

In this section we define satisfaction and power measures for bipartite digraphs which represent a collective decision-making situation as described above. In general, a measure for bipartite digraphs is a function $f: \mathcal{D}^{N} \rightarrow \mathbb{R}^{n}$ which assigns an $n$-dimensional real vector to every bipartite digraph on $N$.

Success of an actor in a voting game means that the voting outcome coincides with the actor's vote. Since in our model actors have their inclinations to chose either the yes- or no-action before they actually choose, we propose to measure the satisfaction of an actor which is related to how often an actor's inclination prior to its actual choice coincides with the collective choice. First, we define satisfaction of an actor under the given inclination vector, i.e., for each $(I, D) \in\{0,1\}^{n} \times \mathcal{D}^{N}$ and $k \in N$

$$
\overline{S A T}_{k}(I, D)=\left\{\begin{array}{l}
1 \text { if } C(I, D)=I_{k} \\
0 \text { otherwise }
\end{array}\right.
$$

Next, based on satisfaction of a voter under each inclination vector, we define satisfaction of actor $k$ in a bipartite digraph, which is measured by $S A T: \mathcal{D}^{N} \rightarrow \mathbb{R}^{n}$ given by

$$
S A T_{k}(D)=\sum_{I \in\{0,1\}^{n}} \overline{S A T}_{k}(I, D) \text { for each } k \in N .
$$

Even more frequently than measuring success, the voting literature studies measures of power or decisiveness of an actor. Roughly speaking, we ascribe power to a successful actor in a voting game if given the votes of the others, by changing its vote the actor changes the voting outcome, i.e. the actor has a swing. Since we consider situations where the actors have their inclinations before they choose their action, and the power of an actor is related to its ability to alter the collective choice, we can relate the power of an actor in this model to its inclination. Consequently, we ascribe power to an actor if the actor, by changing its inclination alters the collective choice.

Actor $k \in N$ has a swing in $(I, D)$ according to collective decision function $C$ if $C(I, D) \neq C\left(I^{\prime}, D\right)$ with $I_{k}^{\prime} \neq I_{k}$ and $I_{j}^{\prime}=I_{j}$ for all $j \in N \backslash\{k\}$. We measure power under the given inclination vector by the number of swings:

$$
\overline{P O W}_{k}(I, D)= \begin{cases}1 & \text { if } k \text { has a swing in }(I, D) \\ 0 & \text { otherwise. }\end{cases}
$$


Then, power in a digraph is measured by $P O W: \mathcal{D}^{N} \rightarrow \mathbb{R}^{n}$ given by

$$
P O W_{k}(D)=\sum_{I \in\{0,1\}^{n}} \overline{P O W}_{k}(I, D) \text { for each } k \in N .
$$

In the next section we will study common properties of the satisfaction and power measures given by (4) and (5). The only property studied in this paper which is different for both measures concerns the normalization.

\section{Axioms for measures of satisfaction and power based on following a qualified majority of opinion leaders}

Let us consider the measures $S A T$ and $P O W$ defined in (4) and (5), respectively. Each follower is assumed to follow a qualified majority of its opinion leaders, i.e. the choice vector $V$ is as defined in (2). We consider a neutral and anonymous collective decision function $C$ as defined in (3).

First, we state the axioms for a measure $f: \mathcal{D}^{N} \rightarrow \mathbb{R}^{n}$, and then we prove that $S A T$ and $P O W$ satisfy these axioms. The first axiom says that actors with a symmetric position in the bipartite digraph have the same measure.

Axiom 1 (Symmetry) If $S_{D}(k)=S_{D}(j)$ and $P_{D}(k)=P_{D}(j)$ then $f_{k}(D)=f_{j}(D)$.

According to the second axiom, referred to as power neutrality, if an actor becomes a sole opinion leader of another actor who was previously independent, then the sum of the measures of these two actors does not change. In other words, the gain for the opinion leader goes fully at the cost of the follower ${ }^{2}$.

Axiom 2 (Power neutrality) Let $D, D^{\prime} \in \mathcal{D}^{N}$ and $h, j \in N$ be such that $P_{D}(j)=\emptyset$, $h \in O L(D) \cup I N D(D)$ and $D^{\prime}=D \cup\{(h, j)\}$. Then $f_{h}\left(D^{\prime}\right)+f_{j}\left(D^{\prime}\right)=f_{h}(D)+f_{j}(D)$.

The third axiom is the equal or opposite gain property, and states that if a follower gets one more opinion leader, then the changes in measures of this follower and of its new opinion leader are either the same or are opposite. In other words, the absolute values of these changes in measures are the same.

Axiom 3 (Equal or opposite gain property) Let $D, D^{\prime} \in \mathcal{D}^{N}$ and $h, j \in N$ be such that $P_{D}(j) \neq \emptyset, h \in O L(D) \cup I N D(D)$ and $D^{\prime}=D \cup\{(h, j)\}$. Then either $f_{h}\left(D^{\prime}\right)-f_{h}(D)=$ $f_{j}\left(D^{\prime}\right)-f_{j}(D)$ or $f_{h}\left(D^{\prime}\right)-f_{h}(D)=f_{j}(D)-f_{j}\left(D^{\prime}\right)$.

In a particular case, if a follower follows its opinion leaders only if they are unanimous, then a stronger version of this axiom can be imposed, saying that the change in measure of the follower and its new opinion leader is the same. However, this stronger version is not satisfied by our measures if the qualified majority of the opinion leaders, with an arbitrary $q \in\left[\frac{1}{2}, 1\right)$, is assumed.

\footnotetext{
${ }^{2}$ This type of axiom is introduced in the context of cooperative TU-games in Lehrer (1988, [30]) and Haller $(1994,[23])$, and applied to cooperative games with hierarchical permission structures on the set of players in van den Brink (2000, [8]).
} 
The fourth axiom, called the opposite gain property for two opinion leaders, says that if a follower with one opinion leader gets a second opinion leader, then the sum of measures of the 'old' and new opinion leaders does not change. In other words, the change for the new (second) opinion leader is opposite but in absolute value equal to the change for the old (first) opinion leader.

Axiom 4 (Opposite gain property for two opinion leaders) Let $D, D^{\prime} \in \mathcal{D}^{N}$ and $h, j, g \in N$ be such that $P_{D}(j)=\{g\}, h \in O L(D) \cup I N D(D)$ and $D^{\prime}=D \cup\{(h, j)\}$. Then $f_{h}\left(D^{\prime}\right)-f_{h}(D)=f_{g}(D)-f_{g}\left(D^{\prime}\right)$.

If a follower follows only unanimous opinion leaders, then a stronger version of this axiom can be imposed, where the number of the opinion leaders is arbitrary. This stronger version of the axiom is however violated by our measures with the qualified majority of the opinion leaders, with an arbitrary $q \in\left[\frac{1}{2}, 1\right)$.

The fifth axiom is the dictator property and says that if there is a dictator, i.e. a unique opinion leader which is followed by all other actors, then the measure of the dictator is equal to the total number of possible inclination vectors. Note that since we assume that no actor can be at the same time a follower and an opinion leader, the dictator as defined above cannot be a follower.

Axiom 5 (Dictator property) If $D \in \mathcal{D}^{N}$ and $h \in N$ is such that $S_{D}(h)=N \backslash\{h\}$, then $f_{h}(D)=2^{n}$.

According to the sixth axiom, called dictated independence, the measure of a follower with one opinion leader does not change as long as this follower is dictated by a sole opinion leader.

Axiom 6 (Dictated independence) If $D, D^{\prime} \in \mathcal{D}^{N}$ and $k \in N$ are such that $\left|P_{D}(k)\right|=$ $\left|P_{D^{\prime}}(k)\right|=1$, then $f_{k}(D)=f_{k}\left(D^{\prime}\right)$.

As we show later, the measures for satisfaction and power defined in the previous section both satisfy the above six axioms. They differ with respect to a normalization that is applied.

In satisfaction normalization, the sum of all measures is equal to the total number of individual satisfactions over all inclination vectors. On the other hand, in power normalization, the sum of all measures is equal to the total number of swings over all inclination vectors.

Axiom 7 (Satisfaction normalization) For every $D \in \mathcal{D}^{N}$ it holds that

$$
\sum_{k \in N} f_{k}(D)=\sum_{I \in\{0,1\}^{n}} \sum_{k \in N} \overline{S A T}_{k}(I, D) .
$$

Axiom 8 (Power normalization) For every $D \in \mathcal{D}^{N}$ it holds that

$$
\sum_{k \in N} f_{k}(D)=\sum_{I \in\{0,1\}^{n}} \sum_{k \in N} \overline{P O W}_{i}(I, D)
$$


Next, we state the main results which are proved in the Appendix. We show that the satisfaction measure satisfies Axioms 1 till 7 if the choice vector is defined by (2).

Theorem 1 Let the choice vector $V$ be defined by (2). The satisfaction measure $S A T$ : $\mathcal{D}^{N} \rightarrow \mathbb{R}^{n}$ defined in (4) satisfies symmetry, power neutrality, the equal or opposite gain property, the opposite gain property for two opinion leaders, the dictator property, dictated independence and satisfaction normalization.

We also analyze the properties of the power measure $P O W$. It turns out that the power measure $P O W$ satisfies Axioms 1 till 6 and 8, if the choice vector is defined by (2).

Theorem 2 Let the choice vector $V$ be defined by (2). The power measure POW: $\mathcal{D}^{N} \rightarrow$ $\mathbb{R}^{n}$ defined in (5) satisfies symmetry, power neutrality, the equal or opposite gain property, the opposite gain property for two opinion leaders, the dictator property, dictated independence and power normalization.

The symmetry, dictator property and satisfaction normalization imply that the measure $S A T$ also satisfies the dictator domination satisfaction property stating that in case there is a dictator, i.e. a unique opinion leader which is followed by all other actors, the measure of each follower is equal to half of the measure of the dictator.

Axiom 9 (Dictator domination satisfaction property) If $D \in \mathcal{D}^{N}$ and $h \in N$ is such that $S_{D}(h)=N \backslash\{h\}$, then $f_{k}(D)=\frac{1}{2} f_{h}(D)$ for all $k \in N \backslash\{h\}$.

Similar, the symmetry, dictator property and power normalization imply that the measure $P O W$ satisfies the dictator domination power property, which states that in case there is a dictator, the measure of each follower is equal to zero.

Axiom 10 (Dictator domination power property) If $D \in \mathcal{D}^{N}$ and $h \in N$ is such that $S_{D}(h)=N \backslash\{h\}$, then $f_{k}(D)=0$ for all $k \in N \backslash\{h\}$.

Corollary 1 Let the choice vector $V$ be defined by (2). Then, the satisfaction measure $S A T: \mathcal{D}^{N} \rightarrow \mathbb{R}^{n}$ defined in (4) satisfies the dictator domination satisfaction property, and the power measure POW: $\mathcal{D}^{N} \rightarrow \mathbb{R}^{n}$ defined in (5) satisfies the dictator domination power property.

Finally, one can note that from the proof that $S A T$ satisfies the equal or opposite gain property (see the proof of Theorem 1 presented in the Appendix) it follows that, for every $D, D^{\prime} \in \mathcal{D}^{N}$ and $h, j \in N$ such that $P_{D}(j) \neq \emptyset, h \in O L(D) \cup \operatorname{IND}(D)$ and $D^{\prime}=D \cup\{(h, j)\}$, whenever $S A T_{h}\left(I, D^{\prime}\right)-S A T_{h}(I, D)=S A T_{j}\left(I, D^{\prime}\right)-S A T_{j}(I, D)=1$, the follower $j$ votes according to his own inclination in $I \in\{0,1\}^{n}$, i.e., $V_{j}\left(I, D^{\prime}\right)=I_{j}$.

\section{$5 \quad$ Examples}

In order to illustrate the developed measures and obtained results we analyze a society consisting out of five actors, i.e. $N=\{1,2,3,4,5\}$. We assume eight potential opinion leader-follower structures for this society, each represented by a digraph. For the followers 
we assume three different levels of the qualified majorities of the opinion leaders required to adapt their own behavior, i.e.,

$$
q=\frac{1}{2}, \quad q^{\prime}=\frac{2}{3}, \quad q^{\prime \prime}=\frac{3}{4} .
$$

We analyze the following digraphs:

$D_{0}=\emptyset$ (Figure 1a, no opinion leaders)

$D_{1}=\{(2,1)\}$ (Figure $1 \mathrm{~b}$, actor 2 is the sole opinion leader of actor 1 )

$D_{2}=\{(2,1),(3,1)\}$ (Figure 1c, actors 2 and 3 are the opinion leaders of actor 1 )

$D_{3}=\{(2,1),(3,1),(4,1)\}$ (Figure $1 \mathrm{~d}$, actors 2,3 and 4 are the opinion leaders of 1$)$

$D_{4}=\{(2,1),(3,1),(4,1),(5,1)\}$ (Figure 1e, actors in $N \backslash\{1\}$ are the opinion leaders of 1 )

$D_{5}=\{(1,2),(1,3),(1,4),(1,5)\}$ (Figure 1f, actor 1 is a dictator)

$D_{6}=\{(1,2),(3,4)\}$ (Figure 1g, actor 2 follows 1 , actor 4 follows 3 )

$D_{7}=\{(1,2),(3,4),(5,4)\}$ (Figure 1h, actor 2 follows 1, actors 3 and 5 are the opinion leaders of 4$)$.

For this setup we show how the number of opinion leaders affects the relations between actors' measures of satisfaction and power.

Figures $1 \mathrm{a}-1 \mathrm{~h}$ present the graphs $D_{0}-D_{7}$.

\section{FIGURE 1 ABOUT HERE}

Note that in digraph $D_{3}$, in which actor 1 has three opinion leaders, when following the qualified majority of its opinion leaders, under $q=\frac{1}{2}$, actor 1 will always decide according to the inclination of at least two of its opinion leaders with the same inclination. Under $q^{\prime}=\frac{2}{3}$ and $q^{\prime \prime}=\frac{3}{4}$, it will follow its opinion leaders only when they are unanimous. In digraph $D_{4}$, in which actor 1 has four opinion leaders, under $q$ and $q^{\prime}$ actor 1 will follow at least three unanimous opinion leaders, but it will decide according to its own inclination if two of its opinion leaders have the positive inclination, and two have the negative inclination. Under $q^{\prime \prime}$ agent 1 follows its opinion leaders $2,3,4,5$, only if they are unanimous in their inclinations. When an actor has two opinion leaders, like in $D_{2}$ and $D_{7}$, following the qualified majority of the opinion leaders means, of course, following the opinion leaders only when they both are unanimous.

Tables 1 and 2 present the chosen actions and the collective choices based on the collective decision function as given in (3) for digraphs $D_{0}$ till $D_{3}$, and $D_{4}$ till $D_{7}$, respectively. The sign "-" means that for a given $I$, the result (either the chosen action or the collective choice) is the same as in $D_{0}$.

\section{TABLE 1 ABOUT HERE}




\section{TABLE 2 ABOUT HERE}

In Table 3, the measures of actors' satisfaction and power in situations represented by digraphs $D_{0}$ till $D_{7}$ are shown.

\section{TABLE 3 ABOUT HERE}

Using the measures calculated in Table 3, we can illustrate the axioms presented in Section 4. Symmetry is obviously satisfied by both measures in all digraphs. Power neutrality can be seen when comparing $D_{0}$ with $D_{1}$, and $D_{1}$ with $D_{6}$. Indeed, for the latter case, we have:

$$
S A T_{4}\left(D_{1}\right)+S A T_{3}\left(D_{1}\right)=20+20=16+24=S A T_{4}\left(D_{6}\right)+S A T_{3}\left(D_{6}\right)
$$

and

$$
P O W_{4}\left(D_{1}\right)+P O W_{3}\left(D_{1}\right)=8+8=0+16=P O W_{4}\left(D_{6}\right)+P O W_{3}\left(D_{6}\right) .
$$

The measures of satisfaction and power of actors in digraph $D_{5}$ with actor 1 as a dictator, satisfy the dictator property, dictator domination satisfaction property, and the dictator domination power property. Dictated independence can be illustrated with the measures in question of actor 1 in $D_{1}$, actors 2 and 4 in $D_{6}$, and actor 2 in $D_{7}$, with satisfaction always equal to 16 , and power always equal to 0 .

In order to illustrate the equal or opposite gain property, let us first consider digraphs $D_{2}$ and $D_{3}$ with $q=\frac{1}{2}$, where the follower 1 , having already two opinion leaders in $D_{2}$ (players 2 and 3 ), gets his new opinion leader in $D_{3}$, voter 4 . The following holds:

$$
S A T_{4}\left(D_{3}\right)-S A T_{4}\left(D_{2}\right)=24-20=20-16=S A T_{1}\left(D_{2}\right)-S A T_{1}\left(D_{3}\right)
$$

and

$$
P O W_{4}\left(D_{3}\right)-P O W_{4}\left(D_{2}\right)=16-8=8-0=P O W_{1}\left(D_{2}\right)-P O W_{1}\left(D_{3}\right) .
$$

On the other hand, when considering $D_{3}$ and $D_{4}$ with $q=\frac{1}{2}$, where player 5 becomes a new opinion leader of voter 1 , we have:

$$
S A T_{5}\left(D_{4}\right)-S A T_{5}\left(D_{3}\right)=22-16=S A T_{1}\left(D_{4}\right)-S A T_{1}\left(D_{3}\right)
$$

and

$$
P O W_{5}\left(D_{4}\right)-P O W_{5}\left(D_{3}\right)=12-0=P O W_{1}\left(D_{4}\right)-P O W_{1}\left(D_{3}\right) .
$$

The opposite gain property for two opinion leaders can be shown when comparing $D_{1}$ with $D_{2}$, and $D_{6}$ with $D_{7}$. Indeed, for the follower 1 in $D_{1}$ and $D_{2}$, and actors 2 and 3 as actor 1's opinion leaders, we get as follows:

$$
S A T_{2}\left(D_{1}\right)+S A T_{3}\left(D_{1}\right)=28+20=24+24=S A T_{2}\left(D_{2}\right)+S A T_{3}\left(D_{2}\right)
$$

and

$$
P O W_{2}\left(D_{1}\right)+P O W_{3}\left(D_{1}\right)=24+8=16+16=P O W_{2}\left(D_{2}\right)+P O W_{3}\left(D_{2}\right) .
$$


We want to wind up this section with some observations on the satisfaction, power and resulting outcome effects of different opinion leader-follower structures. Comparing $D_{0}$ with $D_{3}$ for $q^{\prime}$ and $q^{\prime \prime}$ and $D_{4}$ for $q, q^{\prime}$ and $q^{\prime \prime}$ from Tables 1 and 2, we can find that for all actors' satisfaction and power is always identical, i.e. it has no effect whether an actor is an opinion leader, follower, or independent actor or whether the society is structured in one way or the other. Moreover, if actors become opinion leaders or followers they have no effect on the outcome. Hence, from a marketing perspective for these structures it does not matter whether there exists no or three or four opinion leaders if there is only up to one follower. However, to establish an opinion leader in a society without any opinion leader (moving from $D_{0}$ to $D_{1}$ ) has some effect on the outcome of the collective choice: it changes in 18.75 percent of the cases, but adding another opinion leader to it (moving from $D_{1}$ to $D_{2}$ ) decreases the number of cases where the outcome changes. In contrast to the case without an opinion leader, the outcome alters on in 6.25 percent of the cases. Hence, the existence of only one opinion leader has a stronger effect to society as having a second one if there exists only one follower.

\section{Concluding remarks}

The existence of opinion leaders and their influence over other actors can be seen in every day life situations: in small as well as in large societies be it in politics or business. Both satisfaction and power are the very natural measures of agents' strength or status in such situations. Since both are different concepts, it is worth to analyze what the common and different properties of the measures for both concepts display. Although, as mentioned in the introduction, there exist several related theoretical studies in the literature on voting models and on networks, the approach which we use in the paper, i.e. the analysis of opinion leader-follower structures and the properties of the measures in question has brought up several innovative elements and can also be regarded to contribute to knowledge in marketing.

However, there are several improvements we could bring to this framework in our future research. First of all, it will be important to deliver the full axiomatic characterizations of the satisfaction and power measures, which would show a difference between the measures from the axiomatic point of view. Moreover, we assume that an actor cannot be at the same time the opinion leader for some actor(s) and the followers of some other actor(s). In a future research on this topic, we could try to relax this assumption and to consider a more general digraph, allowing the sets of predecessors and successors of a given player to be both non empty. Nevertheless, we must admit that the analysis of such a general digraph will be far more complicated than the one delivered in the present paper.

Furthermore, we could apply the same approach to some related models on organizational hierarchies based on subordinates and their superiors (see, e.g., Hammond and Thomas, 1990, [24]), where an organizational choice is to be made. Although such topics are naturally related to our present work, we expect that results on the properties of the measures in question in the superior-subordinate structures will be quite different from the ones obtained in the present model.

Since we consider the two-action model, a natural and useful generalization of the framework will be to enlarge the set of possible actions, i.e., to follow some works on 
abstention (see, e.g. Braham and Steffen, 2002, Felsenthal and Machover, 1997, 1998, 2001, Tchantcho et al., 2008, [7, 14-16,37]), and on multi-choice games (see e.g. Grabisch and Rusinowska, 2008, and Hsiao and Raghavan, 1993, [20,26]). Related models are also games with $r$ alternatives, where the alternatives are not ordered; see Bolger $(1986,1993$, 2000, 2002, [2-5]). Also in Freixas (2005a, 2005b, [17, 18]) and Freixas and Zwicker (2003, [19]), the authors consider decision-making situations, i.e. voting systems, with several levels of approval in the input and output, where those levels are qualitatively ordered. They introduce $(j, k)$ simple games, in which each actor expresses one of $j$ possible levels of input support, and the output consists of one of $k$ possible levels of collective support.

\section{References}

1. J. Banzhaf. Weighted voting doesn't work: a mathematical analysis. Rutgers Law Review, 19:317-343, 1965.

2. E. M. Bolger. Power indices for multicandidate voting games. International Journal of Game Theory, 14:175-186, 1986.

3. E. M. Bolger. A value for games with $n$ players and $r$ alternatives. International Journal of Game Theory, 22:319-334, 1993.

4. E. M. Bolger. A consistent value for games with $n$ players and $r$ alternatives. International Journal of Game Theory, 29:93-99, 2000.

5. E. M. Bolger. Characterizations of two power indices for voting games with $r$ alternatives. Social Choice and Welfare, 19:709-721, 2002.

6. L.R. Bostian. The two-step flow theory: Cross-cultural implications. Journalism Quarterly, 47:109-117, 1970.

7. M. Braham and F. Steffen. Voting power in games with abstentions. In M.J. Holler, H. Kliemt, D. Schmidtchen, and M.E. Streit, editors, Power and Fairness, pages 333-348. Mohr-Siebeck, 2002.

8. R. Brink van den. Axiomatizations of Banzhaf permission values for games with a permission structure. Technical Report 341, Department of Mathematics, University of Texas at Arlington, Arlington, Texas, USA, 2000.

9. R. Brink van den and P. Borm. Digraph competitions and cooperative games. Theory and Decision, 53:327$342,2002$.

10. R. Brink van den and R. P. Gilles. Measuring domination in directed networks. Social Networks, 22:141-157, 2000.

11. P. J. Deutschmann and W. Danielson. Diffusion of knowledge of the major new story. Journalism Quarterly, $37: 345-355,1960$.

12. P. Dubey and L. S. Shapley. Mathematical properties of the Banzhaf power index. Mathematics of Operations Research, 4:99-131, 1979.

13. D. M. Estlund. Opinion leaders, independence, and Condorcet's jury theorem. Theory and Decision, 36:131162, 1994.

14. D. Felsenthal and M. Machover. Ternary voting games. International Journal of Game Theory, 26:335-351, 1997.

15. D. Felsenthal and M. Machover. The Measurement of Voting Power: Theory and Practice, Problems and Paradoxes. London: Edward Elgar Publishers, 1998.

16. D. Felsenthal and M. Machover. Models and reality: the curious case of the absent abstention. In M. J. Holler and G. Owen, editors, Power Indices and Coalition Formation, pages 87-103. Kluwer, Dordrecht, 2001.

17. J. Freixas. Banzhaf measures for games with several levels of approval in the input and output. Annals of Operations Research, 137:45-66, 2005.

18. J. Freixas. The Shapley-Shubik power index for games with several levels of approval in the input and output. Decision Support Systems, 39:185-195, 2005.

19. J. Freixas and W. S. Zwicker. Weighted voting, abstention, and multiple levels of approval. Social Choice and Welfare, 21:399-431, 2003.

20. M. Grabisch and A. Rusinowska. Measuring influence among players with an ordered set of possible actions. GATE Working Paper, 2008-01, GATE, Ecully, France, 2008.

21. M. Granovetter. Threshold models of collective behavior. American Journal of Sociology, 83:1420-1443, 1978.

22. M. Granovetter and R. Soong. Threshold models of interpersonal effects in consumer demand. Journal of Economic Behavior and Organization, 7:83-99, 1986.

23. H. Haller. Collusion properties of values. International Journal of Game Theory, 23:261-281, 1994. 
24. T. H. Hammond and P. Thomas. Invisible decisive coalitions in large hierarchies. Public Choice, 66:101-116, 1990.

25. W. D. Hoyer and N. E. Stokburger-Sauer. A comparison of antecedents and consequences of market mavens and opinion leaders. In T. Bayón, A. Herrmann, F. Huber, M. Hammerschmidt, and N. Stokburger-Sauer, editors, Vielfalt und Einheit in der Marketingwissenschaft - Ein Spannungsverhältnis, pages 215-236. Gabler, 2007.

26. C. R. Hsiao and T. E. S. Raghavan. Shapley value for multichoice cooperative games. Games and Economic Behavior, 5:240-256, 1993.

27. E. Katz and P. F. Lazarsfeld. Personal Influence: The Part Played by People in the Flow of Mass Communication. Free Press, 1955.

28. A. Laruelle and F. Valenciano. Assessing success and decisiveness in voting situations. Social Choice and Welfare, 24:171-197, 2005.

29. P. F. Lazarsfeld, B. Berelson, and H. Gaudet. The People's Choice - How the Voter Makes up his Mind in a Presidential Campaign. Columbia University Press, 1968. 3rd ed., the first edition of this book was published in 1944.

30. E. Lehrer. An axiomatization of the Banzhaf value. International Journal of Game Theory, 17:89-99, 1988.

31. G. Owen. Multilinear extensions and the Banzhaf value. Naval Research Logistic Quarterly, 22:741-750, 1975.

32. D. Rae. Decision-rules and individual values in constitutional choice. American Political Science Review, 63:40-56, 1969.

33. L. S. Shapley and M. Shubik. A method for evaluating the distribution of power in a committee system. American Political Science Review, 48:787-792, 1954.

34. S. Sinha and S. Raghavendra. Emergence of two-phase behavior in markets through interaction and learning in agents with bounded rationality. In Practical Fruits of Econophysics: Proceedings of the 3rd Nikkei Econophysics Symposium, pages 200-204. Springer, 2006.

35. P. D. Straffin. Homogeneity, independence, and power indices. Public Choice, 30:107-118, 1977.

36. P. D. Straffin. Probability models for power indices. In P. C. Ordeshook, editor, Game Theory and Political Science, pages 477-510. New York University Press, 1978.

37. B. Tchantcho, L. Diffo Lambo, R. Pongou, and B. Mbama Engoulou. Voters' power in voting games with abstention: Influence relation and ordinal equivalence of power theories. Games and Economic Behavior, 64:335-350, 2008.

38. V. C. Troldahl. A field test of a modified 'two-step flow of communication' model. Public Opinion Quarterly, 30:609-623, 1966. 


\section{Appendix}

In this appendix we provide all proofs of the results in this paper.

\section{Proof of Theorem 1}

It is straightforward that $S A T$ satisfies symmetry and satisfaction normalization.

To show power neutrality, let $D, D^{\prime} \in \mathcal{D}^{N}$ and $h, j \in N$ be such that $P_{D}(j)=\emptyset$, $h \in O L(D) \cup I N D(D)$ and $D^{\prime}=D \cup\{(h, j)\}$. If $C(I, D) \neq C\left(I, D^{\prime}\right)$ then it must hold that actor $j$ had to deviate from its inclination and follow $h$, and this must result in a change of collective choice from $I_{j}$ to $I_{h}$, with $I_{j} \neq I_{h}$. So, $C(I, D)=I_{j} \neq I_{h}$ and $C\left(I, D^{\prime}\right)=$ $I_{h} \neq I_{j}$. Then, $\overline{S A T}_{j}\left(I, D^{\prime}\right)=\overline{S A T}_{j}(I, D)-1$ and $\overline{S A T}_{h}\left(I, D^{\prime}\right)=\overline{S A T}_{h}(I, D)+1$. So, $\overline{S A T}_{j}\left(I, D^{\prime}\right)+\overline{S A T}_{h}\left(I, D^{\prime}\right)=\overline{S A T}_{j}(I, D)+\overline{S A T}_{h}(I, D)$. Obviously, this last equality also holds if $C(I, D)=C\left(I, D^{\prime}\right)$. Thus, with (4) we have $S A T_{j}\left(D^{\prime}\right)+S A T_{h}\left(D^{\prime}\right)=S A T_{j}(D)+$ $S A T_{h}(D)$, showing that $S A T$ satisfies power neutrality.

To show the equal or opposite gain property, let $D, D^{\prime} \in \mathcal{D}^{N}$ and $h, j \in N$ be such that $P_{D}(j) \neq \emptyset, h \in O L(D) \cup I N D(D)$ and $D^{\prime}=D \cup\{(h, j)\}$. For all inclination vectors $I$ such that $C(I, D)=C\left(I, D^{\prime}\right)$, obviously it holds $\overline{S A T}_{j}\left(I, D^{\prime}\right)-\overline{S A T}_{j}(I, D)=0=$ $\overline{S A T}_{h}\left(I, D^{\prime}\right)-\overline{S A T}_{h}(I, D)$.

Let $I \in\{0,1\}^{n}$ be such that $C(I, D) \neq C\left(I, D^{\prime}\right)$. Then, $C(I, D) \neq I_{h}$ and $C\left(I, D^{\prime}\right)=I_{h}$, and therefore $\overline{S A T}_{h}\left(I, D^{\prime}\right)-\overline{S A T}_{h}(I, D)=1$.

Case I: If $\left[q \cdot\left|P_{D}(j)\right|\right]=q \cdot\left|P_{D}(j)\right|$ and $C(I, D) \neq C\left(I, D^{\prime}\right)$ for some $I$, then $q \cdot\left|P_{D}(j)\right|$ opinion leaders of $j$ have inclination $x=I_{h} \neq I_{j}, V_{j}(I, D)=I_{j}, C(I, D)=I_{j}$, but $V_{j}\left(I, D^{\prime}\right)=$ $I_{h}, C\left(I, D^{\prime}\right)=I_{h} \neq I_{j}$. Then, $\overline{S A T}_{j}(I, D)-\overline{S A T}_{j}\left(I, D^{\prime}\right)=1=\overline{S A T}_{h}\left(I, D^{\prime}\right)-\overline{S A T}_{h}(I, D)$, and with (4) we get $S A T_{h}\left(D^{\prime}\right)-S A T_{h}(D)=S A T_{j}(D)-S A T_{j}\left(D^{\prime}\right)$.

Case II: If $\left[q \cdot\left|P_{D}(j)\right|\right]<q \cdot\left|P_{D}(j)\right|$ and $C(I, D) \neq C\left(I, D^{\prime}\right)$ for some $I$, then $\left[q \cdot\left|P_{D}(j)\right|\right]+1$ opinion leaders of $j$ have inclination $x \neq I_{h}=I_{j},\left[q \cdot\left|P_{D}(j)\right|\right]+1=\left[q \cdot\left(\left|P_{D}(j)\right|+\right.\right.$ $1)], V_{j}(I, D) \neq I_{j}, C(I, D) \neq I_{j}$, but $V_{j}\left(I, D^{\prime}\right)=I_{j}=I_{h}$ and $C\left(I, D^{\prime}\right)=I_{j}$. Then, $\overline{S A T}_{j}\left(I, D^{\prime}\right)-\overline{S A T}_{j}(I, D)=1=\overline{S A T}_{h}\left(I, D^{\prime}\right)-\overline{S A T}_{h}(I, D)$, and with (4) we have $S A T_{h}\left(D^{\prime}\right)-S A T_{h}(D)=S A T_{j}\left(D^{\prime}\right)-S A T_{j}(D)$.

Hence, $S A T$ satisfies the equal or opposite gain property.

To show the opposite gain property for two opinion leaders, let $D, D^{\prime} \in \mathcal{D}^{N}$ and $h, j \in N$ be such that $P_{D}(j)=\{g\}, h \in O L(D) \cup \operatorname{IND}(D)$ and $D^{\prime}=D \cup\{(h, j)\}$. Obviously, if $C(I, D)=C\left(I, D^{\prime}\right)$, then $\overline{S A T}_{h}\left(I, D^{\prime}\right)-\overline{S A T}_{h}(I, D)=\overline{S A T}_{g}(I, D)-$ $\overline{S A T}_{g}\left(I, D^{\prime}\right)=0$. Suppose now that $C(I, D) \neq C\left(I, D^{\prime}\right)$. Then it must hold that actor $j$ initially had to choose an action against its inclination and now can choose an action according to its inclination because its new opinion leader $h$ has the same inclination. So, for $g \in P_{D}(j)$ we have $C(I, D)=I_{g} \neq I_{j}=I_{h}$ and $C\left(I, D^{\prime}\right)=I_{j}=I_{h} \neq I_{g}$. Then, $\overline{S A T}_{h}\left(I, D^{\prime}\right)-\overline{S A T}_{h}(I, D)=\overline{S A T}_{g}(I, D)-\overline{S A T}_{g}\left(I, D^{\prime}\right)=1$. Thus, with (4) we have $S A T_{h}\left(D^{\prime}\right)-S A T_{h}(D)=S A T_{g}(D)-S A T_{g}\left(D^{\prime}\right)$, showing that $S A T$ satisfies the opposite gain property for two opinion leaders.

The dictator property follows straightforward since a dictator is followed in all $2^{n}$ inclination vectors in $\{0,1\}^{n}$, i.e., if $S_{D}(h)=N \backslash\{h\}$, then $C(I, D)=I_{h}$ for all $I \in\{0,1\}^{n}$.

To show dictated independence, note that actor $k$ always chooses an action according to $j$ 's inclination if $P_{D}(k)=\{j\}$. That means that the collective choice is independent 
of actor $k$ 's inclination, i.e. $C(I, D)=C\left(I^{\prime}, D\right)$ if $I_{h}=I_{h}^{\prime}$ for all $h \in N \backslash\{k\}$. Hence, in half of the inclination vectors $C(I, D)=I_{k}$ and in the other half $C(I, D) \neq I_{k}$. So, $S A T$ satisfies dictated independence.

\section{Proof of Theorem 2}

It is straightforward that $P O W$ satisfies symmetry and power normalization.

To show power neutrality, let $D, D^{\prime} \in \mathcal{D}^{N}$ and $h, j \in N$ be such that $P_{D}(j)=\emptyset$, $h \in O L(D) \cup I N D(D)$ and $D^{\prime}=D \cup\{(h, j)\}$. Since in $D^{\prime}$ actor $j$ has to choose an action according to its unique opinion leader $h, j$ has never a swing in $D^{\prime}$, i.e. $P O W_{j}\left(D^{\prime}\right)=0$. So, we have to show that $P O W_{h}\left(D^{\prime}\right)=P O W_{h}(D)+P O W_{j}(D)$. We distinguish the following three cases.

(i) If $h$ does not have a swing in $(I, D)$ but $j$ has a swing in $(I, D)$, then $h$ has a swing in $\left(I, D^{\prime}\right)$, i.e. if $P O W_{h}(I, D)=0$ and $P O W_{j}(I, D)=1$ then $P O W_{h}\left(I, D^{\prime}\right)=1$.

(ii) If $h$ has a swing in $(I, D)$, then $h$ has a swing in $\left(I, D^{\prime}\right)$, i.e. if $P O W_{h}(I, D)=1$ then $P O W_{h}\left(I, D^{\prime}\right)=1$. If, moreover, also $j$ has a swing in $(I, D)$ then $h$ has also a swing in $\left(I^{\prime}, D^{\prime}\right)$ with $I_{j}^{\prime}=I_{h}^{\prime} \neq I_{h}=I_{j}$, i.e. if $P O W_{h}(I, D)=1$ and $P O W_{j}(I, D)=1$ then $P O W_{h}\left(I^{\prime}, D^{\prime}\right)=1$.

(iii) Finally, if $h$ does not have a swing in $(I, D)$ and $j$ does not have a swing in $(I, D)$, then the only possibility for $h$ to have a swing in $\left(I, D^{\prime}\right)$ is as described in the last case before. So, $P O W_{h}\left(D^{\prime}\right)=\sum_{I \in\{0,1\}^{n}} \overline{P O W}_{h}\left(I, D^{\prime}\right)=\sum_{I \in\{0,1\}^{n}}\left(\overline{P O W}_{h}(I, D)+\right.$ $\left.\overline{P O W}_{j}(I, D)\right)$, showing that $P O W$ satisfies power neutrality.

To show the equal or opposite gain property, let $D, D^{\prime} \in \mathcal{D}^{N}$ and $h, j \in N$ be such that $P_{D}(j) \neq \emptyset, h \in O L(D) \cup I N D(D)$ and $D^{\prime}=D \cup\{(h, j)\}$. Note that $P O W_{h}(I, D)=1$ implies that $P O W_{h}\left(I, D^{\prime}\right)=1$.

Case I: Suppose that $\left[q \cdot\left|P_{D}(j)\right|\right]=q \cdot\left|P_{D}(j)\right|$. We distinguish the following subcases:

(i) If $I \in\{0,1\}^{n}$ is such that $\left[q \cdot\left|P_{D}(j)\right|\right]+1$ opinion leaders of $j$ have the same inclination, then $P O W_{j}(I, D)=P O W_{j}\left(I, D^{\prime}\right)=0$ and $P O W_{h}(I, D)=P O W_{h}\left(I, D^{\prime}\right)$.

(ii) If $I$ is such that less than $\left[q \cdot\left|P_{D}(j)\right|\right]$ opinion leaders of $j$ have the inclination $x \in\{0,1\}$ and less than $\left[q \cdot\left|P_{D}(j)\right|\right]$ opinion leaders have the inclination $y \in\{0,1\} \backslash\{x\}$, then $P O W_{j}(I, D)=P O W_{j}\left(I, D^{\prime}\right)$ and $P O W_{h}(I, D)=P O W_{h}\left(I, D^{\prime}\right)$.

(iii) Suppose that $I \in\{0,1\}^{n}$ is such that $\left[q \cdot\left|P_{D}(j)\right|\right]$ opinion leaders have the same inclination, say $x \in\{0,1\}$, and less than $\left[q \cdot\left|P_{D}(j)\right|\right]$ have the different inclination $y \in$ $\{0,1\} \backslash\{x\}$.

(a) If $I_{j}=x \neq y=I_{h}$, then $P O W_{j}(I, D)=P O W_{j}\left(I, D^{\prime}\right)$ and $P O W_{h}(I, D)=$ $P O W_{h}\left(I, D^{\prime}\right)$.

(b) Let $x=I_{h} \neq y=I_{j}$. If $P O W_{j}(I, D)=1$, then $P O W_{j}(I, D)-P O W_{j}\left(I, D^{\prime}\right)=1$ and $P O W_{h}\left(I, D^{\prime}\right)-P O W_{h}(I, D)=1$. Moreover, for $I^{\prime} \in\{0,1\}^{n}$ such that $x=I_{j}^{\prime}=$ $I_{h}^{\prime} \neq y, I_{k}^{\prime}=I_{k}$ for $k \notin\{j, h\}, P O W_{j}\left(I^{\prime}, D\right)-P O W_{j}\left(I^{\prime}, D^{\prime}\right)=1$ and $P O W_{h}\left(I^{\prime}, D^{\prime}\right)-$ $P O W_{h}\left(I^{\prime}, D\right)=0$, but for $I^{\prime \prime} \in\{0,1\}^{n}$ such that $x \neq I_{j}^{\prime \prime}=I_{h}^{\prime \prime}=y, I_{k}^{\prime \prime}=I_{k}$ for $k \notin\{j, h\}$, $P O W_{j}\left(I^{\prime \prime}, D\right)-P O W_{j}\left(I^{\prime \prime}, D^{\prime}\right)=0$ and $P O W_{h}\left(I^{\prime \prime}, D^{\prime}\right)-P O W_{h}\left(I^{\prime \prime}, D\right)=1$.

In a similar way we can consider the case when $\left[q \cdot\left|P_{D}(j)\right|\right]+1$ opinion leaders of $j$ have one inclination, and $\left[q \cdot\left|P_{D}(j)\right|\right]+1$ opinion leaders have the other inclination.

Thus, with (5), we get $P O W_{h}\left(D^{\prime}\right)-P O W_{h}(D)=P O W_{j}(D)-P O W_{j}\left(D^{\prime}\right)$.

Case II: Suppose that $\left[q \cdot\left|P_{D}(j)\right|\right]<q \cdot\left|P_{D}(j)\right|$, and $\left[q \cdot\left|P_{D}(j)\right|\right]+1=\left[q \cdot\left(\left|P_{D}(j)\right|+1\right)\right]$. We distinguish the following cases. 
(i) If $I \in\{0,1\}^{n}$ is such that $\left[q \cdot\left|P_{D}(j)\right|\right]+2$ opinion leaders of $j$ have the same inclination, then $P O W_{j}(I, D)=P O W_{j}\left(I, D^{\prime}\right)=0$ and $P O W_{h}(I, D)=P O W_{h}\left(I, D^{\prime}\right)$.

(ii) If $I \in\{0,1\}^{n}$ is such that $\left[q \cdot\left|P_{D}(j)\right|\right]$ (or less) opinion leaders of $j$ have one inclination and less than $\left[q \cdot\left|P_{D}(j)\right|\right]$ opinion leaders have the other inclination, then $P O W_{j}(I, D)=P O W_{j}\left(I, D^{\prime}\right)$ and $P O W_{h}(I, D)=P O W_{h}\left(I, D^{\prime}\right)$.

(iii) Suppose $I$ is such that $\left[q \cdot\left|P_{D}(j)\right|\right]+1$ opinion leaders have the same inclination, say $x \in\{0,1\}$. Then $P O W_{j}(I, D)=0$. There are several possibilities.

(a) If $I_{j}=x=I_{h} \neq y$, then $P O W_{j}\left(I, D^{\prime}\right)=0$ and $P O W_{h}(I, D)=P O W_{h}\left(I, D^{\prime}\right)$.

(b) Suppose $x=I_{h} \neq y=I_{j}$. Then, $P O W_{j}\left(I, D^{\prime}\right)=0$ and if, moreover, $P O W_{h}(I, D)=$ 1 , we have $P O W_{h}\left(I, D^{\prime}\right)=1$. Further, for $I^{\prime} \in\{0,1\}^{n}$ such that $x \neq I_{j}^{\prime}=I_{h}^{\prime}=$ $y, I_{k}^{\prime}=I_{k}$ for $k \notin\{j, h\}, P O W_{h}\left(I^{\prime}, D\right)=P O W_{h}\left(I^{\prime}, D^{\prime}\right)=1$ and $P O W_{j}\left(I^{\prime}, D^{\prime}\right)=$ $P O W_{j}\left(I^{\prime}, D\right)=0$, and for $I^{\prime \prime} \in\{0,1\}^{n}$ such that $x=I_{j}^{\prime \prime} \neq I_{h}^{\prime \prime}=y, I_{k}^{\prime \prime}=I_{k}$ for $k \notin\{j, h\}$, $P O W_{j}\left(I^{\prime \prime}, D\right)=P O W_{j}\left(I^{\prime \prime}, D^{\prime}\right)=0$ and $P O W_{h}\left(I^{\prime \prime}, D^{\prime}\right)=P O W_{h}\left(I^{\prime \prime}, D\right)$. Suppose now that $P O W_{h}(I, D)=0$. If $P O W_{h}\left(I, D^{\prime}\right)=0$ as well, then $P O W_{h}\left(I, D^{\prime}\right)-P O W_{h}(I, D)=$ $P O W_{j}\left(I, D^{\prime}\right)-P O W_{j}(I, D)$, and the same holds for $I^{\prime}$ and $I^{\prime \prime}$. If $P O W_{h}\left(I, D^{\prime}\right)=1$, then $P O W_{h}\left(I, D^{\prime}\right)-P O W_{h}(I, D)=1$ and $P O W_{j}\left(I, D^{\prime}\right)-P O W_{j}(I, D)=0, P O W_{h}\left(I^{\prime}, D^{\prime}\right)-$ $P O W_{h}\left(I^{\prime}, D\right)=1$ and $P O W_{j}\left(I^{\prime}, D^{\prime}\right)-P O W_{j}\left(I^{\prime}, D\right)=1$, but $P O W_{h}\left(I^{\prime \prime}, D^{\prime}\right)-P O W_{h}\left(I^{\prime \prime}, D\right)=0$ and $P O W_{j}\left(I^{\prime \prime}, D^{\prime}\right)-P O W_{j}\left(I^{\prime \prime}, D\right)=1$.

Thus, with (5), $P O W_{h}\left(D^{\prime}\right)-P O W_{h}(D)=P O W_{j}\left(D^{\prime}\right)-P O W_{j}(D)$.

Hence, $P O W$ satisfies the equal or opposite gain property.

To show the opposite gain property for two opinion leaders, let $D, D^{\prime} \in \mathcal{D}^{N}$ and $h, j, g \in N$ be such that $P_{D}(j)=\{g\}, h \in O L(D) \cup \operatorname{IND}(D)$ and $D^{\prime}=D \cup\{(h, j)\}$. Note that $P O W_{g}(I, D)=0$ implies that $P O W_{g}\left(I, D^{\prime}\right)=0$. Moreover, $P O W_{h}(I, D)=1$ implies $P O W_{h}\left(I, D^{\prime}\right)=1$.

Note that it is impossible that at the same time $P O W_{h}\left(I, D^{\prime}\right)+P O W_{g}\left(I, D^{\prime}\right) \geq 1$ and $P O W_{h}(I, D)+P O W_{g}(I, D)=0$. Moreover, it is impossible that at the same time $P O W_{h}\left(I, D^{\prime}\right)+P O W_{g}\left(I, D^{\prime}\right) \leq 1$ and $P O W_{h}(I, D)+P O W_{g}(I, D)=2$.

Furthermore, note that $\left[I \in\{0,1\}^{n}\right.$ is such that

$P O W_{h}\left(I, D^{\prime}\right)+P O W_{g}\left(I, D^{\prime}\right)=2$ and $\left.P O W_{h}(I, D)+P O W_{g}(I, D)=1\right]$ if and only if $\left[I_{h}=I_{g} \neq I_{j}\right.$ and for $I^{\prime} \in\{0,1\}^{n}$ given by $I_{h}^{\prime}=I_{g}^{\prime} \neq I_{g}\left(=I_{h}\right)$, and $I_{k}^{\prime}=I_{k}$ for all $k \in N \backslash\{g, h\}$ (and thus $I_{j}^{\prime}=I_{h}^{\prime}=I_{g}^{\prime}$ ), satisfies $P O W_{h}\left(I^{\prime}, D^{\prime}\right)+P O W_{g}\left(I^{\prime}, D^{\prime}\right)=0$ and $\left.P O W_{h}\left(I^{\prime}, D\right)+P O W_{g}\left(I^{\prime}, D\right)=1\right]$.

Hence, $P O W$ satisfies the opposite gain property for two opinion leaders.

Since a dictator has a swing in every inclination vector, $P O W$ satisfies the dictator property. Since an actor with a unique opinion leader never has a swing, $P O W$ satisfies dictated independence.

\section{Proof of Corollary 1}

Let $D \in \mathcal{D}^{N}$ and $h \in N$ be a dictator, i.e., $S_{D}(h)=N \backslash\{h\}$.

From symmetry, the dictator property and satisfaction normalization, we have for each $k \in N \backslash\{h\}, \sum_{j \in N} S A T_{j}(D)=S A T_{h}(D)+(n-1) S A T_{k}(D)=2^{n}+(n-1) S A T_{k}(D)$, and $\sum_{I \in\{0,1\}^{n}} \sum_{j \in N} \overline{S A T}_{j}(I, D)=2^{n}+(n-1) 2^{n-1}$. Hence,

$S A T_{k}(D)=2^{n-1}=\frac{1}{2} S A T_{h}(D)$, showing that $S A T$ satisfies the dictator domination satisfaction property. 
From symmetry, the dictator property and power normalization, we have for each $k \in N \backslash\{h\}, \sum_{j \in N} P O W_{j}(D)=P O W_{h}(D)+(n-1) P O W_{k}(D)=2^{n}+(n-1) P O W_{k}(D)$, and $\sum_{I \in\{0,1\}^{n}} \sum_{j \in N} \overline{P O W}_{j}(I, D)=2^{n}$, and therefore $P O W_{k}(D)=0$, showing that $P O W$ satisfies the dictator domination power property. 
Digraph $D_{0}$

(a) $\begin{array}{lllll}\bullet & 2 & 3 & 4 & 5\end{array}$

Digraph $D_{2}$

(c) $\left.2\right|_{1} ^{3} \quad \stackrel{4}{\bullet} \quad$

Digraph $D_{4}$

(e) 2

Digraph $D_{6}$
(g) \begin{tabular}{rrr}
1 & 3 & 5 \\
\hdashline & & \\
$\bullet$ & &
\end{tabular}

Digraph $D_{1}$

(b) \begin{tabular}{llll}
2 & 3 & 4 & 5 \\
\hdashline
\end{tabular}

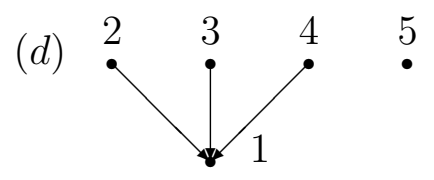

Digraph $D_{5}$

(f)

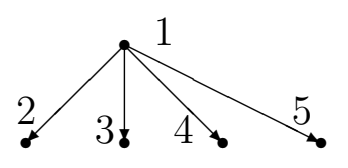

Digraph $D_{7}$

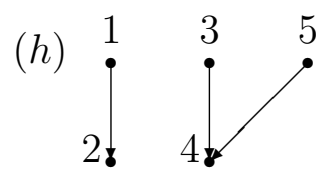

Figure 1: Digraphs $D_{0}-D_{7}$ 


\begin{tabular}{|c|c|c|c|c|c|c|c|c|c|}
\hline$I=V\left(I, D_{0}\right)$ & $C(I, V)$ & $V\left(I, D_{1}\right)$ & $C(I, V)$ & $V\left(I, D_{2}\right)$ & $C(I, V)$ & \begin{tabular}{|c|}
$V\left(I, D_{3}\right)$ \\
with $q$ \\
\end{tabular} & \begin{tabular}{|l|}
$C(I, V)$ \\
with $q$ \\
\end{tabular} & \begin{tabular}{|c|}
$V\left(I, D_{3}\right)$ \\
with $q^{\prime}, q^{\prime \prime}$
\end{tabular} & \begin{tabular}{|c|}
$C(I, V)$ \\
with $q^{\prime}, q^{\prime \prime}$ \\
\end{tabular} \\
\hline$(0,0,0,0,0)$ & 0 & - & - & - & - & - & - & - & - \\
\hline$(1,0,0,0,0)$ & 0 & $(0,0,0,0,0)$ & - & $(0,0,0,0,0)$ & - & $(0,0,0,0,0)$ & - & $(0,0,0,0,0)$ & - \\
\hline$(0,1,0,0,0)$ & 0 & $(1,1,0,0,0)$ & - & - & - & - & - & - & - \\
\hline$(0,0,1,0,0)$ & 0 & - & - & - & - & - & - & - & - \\
\hline$(0,0,0,1,0)$ & 0 & - & - & - & - & - & - & - & - \\
\hline$(0,0,0,0,1)$ & 0 & - & - & - & - & - & - & - & - \\
\hline$(1,1,0,0,0)$ & 0 & - & - & - & - & $(0,1,0,0,0)$ & - & - & - \\
\hline$(1,0,1,0,0)$ & 0 & $(0,0,1,0,0)$ & - & - & - & $(0,0,1,0,0)$ & - & - & - \\
\hline$(1,0,0,1,0)$ & 0 & $(0,0,0,1,0)$ & - & $(0,0,0,1,0)$ & - & $(0,0,0,1,0)$ & - & - & - \\
\hline$(1,0,0,0,1)$ & 0 & $(0,0,0,0,1)$ & - & $(0,0,0,0,1)$ & - & $(0,0,0,0,1)$ & - & $(0,0,0,0,1)$ & - \\
\hline$(0,1,1,0,0)$ & 0 & $(1,1,1,0,0)$ & 1 & $(1,1,0,0,0)$ & 1 & $(1,1,1,0,0)$ & 1 & - & - \\
\hline$(0,1,0,1,0)$ & 0 & $(1,1,0,1,0)$ & 1 & - & - & $(1,1,0,1,0)$ & 1 & - & - \\
\hline$(0,1,0,0,1)$ & 0 & $(1,1,0,0,1)$ & 1 & - & - & - & - & - & - \\
\hline$(0,0,1,1,0)$ & 0 & - & - & - & - & $(1,0,1,1,0)$ & 1 & - & - \\
\hline$(0,0,1,0,1)$ & 0 & - & - & - & - & - & - & - & - \\
\hline$(0,0,0,1,1)$ & 0 & - & - & - & - & - & - & - & - \\
\hline$(1,1,1,0,0)$ & 1 & - & - & - & - & - & - & - & - \\
\hline$(1,1,0,1,0)$ & 1 & - & - & - & - & - & - & - & - \\
\hline$(1,1,0,0,1)$ & 1 & - & - & - & - & $(0,1,0,0,1)$ & 0 & - & - \\
\hline$(1,0,1,1,0)$ & 1 & $(0,0,1,1,0)$ & 0 & - & - & - & - & - & - \\
\hline$(1,0,1,0,1)$ & 1 & $(0,0,1,0,1)$ & 0 & - & - & $(0,0,1,0,1)$ & 0 & - & - \\
\hline$(1,0,0,1,1)$ & 1 & $(0,0,0,1,1)$ & 0 & $(0,0,0,1,1)$ & 0 & $(0,0,0,1,1)$ & 0 & - & - \\
\hline$(0,1,1,1,0)$ & 1 & $(1,1,1,1,0)$ & - & $(1,1,1,1,0)$ & - & $(1,1,1,1,0)$ & - & $(1,1,1,1,0)$ & - \\
\hline$(0,1,1,0,1)$ & 1 & $(1,1,1,0,1)$ & - & $(1,1,1,0,1)$ & - & $(1,1,1,0,1)$ & - & - & - \\
\hline$(0,1,0,1,1)$ & 1 & $(1,1,0,1,1)$ & - & - & - & $(1,1,0,1,1)$ & - & - & - \\
\hline$(0,0,1,1,1)$ & 1 & - & - & - & - & $(1,0,1,1,1)$ & - & - & - \\
\hline$(1,1,1,1,0)$ & 1 & - & - & - & - & - & - & - & - \\
\hline$(1,1,1,0,1)$ & 1 & - & - & - & - & - & - & - & - \\
\hline$(1,1,0,1,1)$ & 1 & - & - & - & - & - & - & - & - \\
\hline$(1,0,1,1,1)$ & 1 & $(0,0,1,1,1)$ & - & - & - & - & - & - & - \\
\hline$(0,1,1,1,1)$ & 1 & $(1,1,1,1,1)$ & - & $(1,1,1,1,1)$ & - & $(1,1,1,1,1)$ & - & $(1,1,1,1,1)$ & - \\
\hline$(1,1,1,1,1)$ & 1 & - & - & - & - & - & - & - & - \\
\hline
\end{tabular}

Table 1. Votes and collective decisions for digraphs $D_{0}-D_{3}$ 


\begin{tabular}{|c|c|c|c|c|c|c|c|c|c|c|}
\hline$I$ & \begin{tabular}{|c|}
$V\left(I, D_{4}\right)$ \\
with $q, q^{\prime}$ \\
\end{tabular} & $\begin{array}{r}C(I, V) \\
\text { with } q, q^{\prime} \\
\end{array}$ & $\begin{array}{l}V\left(I, D_{4}\right) \\
\text { with } q^{\prime \prime}\end{array}$ & $\begin{array}{l}C(I, V) \\
\text { with } q^{\prime \prime}\end{array}$ & $V\left(I, D_{5}\right)$ & $C(I, V)$ & $V\left(I, D_{6}\right)$ & $C(I, V)$ & $V\left(I, D_{7}\right)$ & $C(I, V)$ \\
\hline$(0,0,0,0,0)$ & - & - & - & - & $(0,0,0,0,0)$ & - & - & - & - & - \\
\hline$(1,0,0,0,0)$ & $(0,0,0,0,0)$ & - & $(0,0,0,0,0)$ & - & $(1,1,1,1,1)$ & 1 & $(1,1,0,0,0)$ & - & $(1,1,0,0,0)$ & - \\
\hline$(0,1,0,0,0)$ & - & - & - & - & $(0,0,0,0,0)$ & - & $(0,0,0,0,0)$ & - & $(0,0,0,0,0)$ & - \\
\hline$(0,0,1,0,0)$ & - & - & - & - & $(0,0,0,0,0)$ & - & $(0,0,1,1,0)$ & - & $(0,0,1,0,0)$ & - \\
\hline$(0,0,0,1,0)$ & - & - & - & - & $(0,0,0,0,0)$ & - & $(0,0,0,0,0)$ & - & $(0,0,0,0,0)$ & - \\
\hline$(0,0,0,0,1)$ & - & - & - & - & $(0,0,0,0,0)$ & - & - & - & - & - \\
\hline$(1,1,0,0,0)$ & $(0,1,0,0,0)$ & - & - & - & $(1,1,1,1,1)$ & 1 & - & - & - & - \\
\hline$(1,0,1,0,0)$ & $(0,0,1,0,0)$ & - & - & - & $(1,1,1,1,1)$ & 1 & $(1,1,1,1,0)$ & 1 & $(1,1,1,0,0)$ & 1 \\
\hline$(1,0,0,1,0)$ & $(0,0,0,1,0)$ & - & - & - & $(1,1,1,1,1)$ & 1 & $(1,1,0,0,0)$ & - & $(1,1,0,0,0)$ & - \\
\hline$(1,0,0,0,1)$ & $(0,0,0,0,1)$ & - & - & - & $(1,1,1,1,1)$ & 1 & $(1,1,0,0,1)$ & 1 & $(1,1,0,0,1)$ & 1 \\
\hline$(0,1,1,0,0)$ & - & - & - & - & $(0,0,0,0,0)$ & - & $(0,0,1,1,0)$ & - & $(0,0,1,0,0)$ & - \\
\hline$(0,1,0,1,0)$ & - & - & - & - & $(0,0,0,0,0)$ & - & $(0,0,0,0,0)$ & - & $(0,0,0,0,0)$ & - \\
\hline$(0,1,0,0,1)$ & - & - & - & - & $(0,0,0,0,0)$ & - & $(0,0,0,0,1)$ & - & $(0,0,0,0,1)$ & - \\
\hline$(0,0,1,1,0)$ & - & - & - & - & $(0,0,0,0,0)$ & - & - & - & - & - \\
\hline$(0,0,1,0,1)$ & - & - & - & - & $(0,0,0,0,0)$ & - & $(0,0,1,1,1)$ & 1 & $(0,0,1,1,1)$ & 1 \\
\hline$(0,0,0,1,1)$ & - & - & - & - & $(0,0,0,0,0)$ & - & $(0,0,0,0,1)$ & - & - & - \\
\hline$(1,1,1,0,0)$ & - & - & - & - & $(1,1,1,1,1)$ & - & $(1,1,1,1,0)$ & - & - & - \\
\hline$(1,1,0,1,0)$ & - & - & - & - & $(1,1,1,1,1)$ & - & $(1,1,0,0,0)$ & 0 & $(1,1,0,0,0)$ & 0 \\
\hline$(1,1,0,0,1)$ & - & - & - & - & $(1,1,1,1,1)$ & - & - & - & - & - \\
\hline$(1,0,1,1,0)$ & - & - & - & - & $(1,1,1,1,1)$ & - & $(1,1,1,1,0)$ & - & $(1,1,1,1,0)$ & - \\
\hline$(1,0,1,0,1)$ & - & - & - & - & $(1,1,1,1,1)$ & - & $(1,1,1,1,1)$ & - & $(1,1,1,1,1)$ & - \\
\hline$(1,0,0,1,1)$ & - & - & - & - & $(1,1,1,1,1)$ & - & $(1,1,0,0,1)$ & - & $(1,1,0,1,1)$ & - \\
\hline$(0,1,1,1,0)$ & $(1,1,1,1,0)$ & - & - & - & $(0,0,0,0,0)$ & 0 & $(0,0,1,1,0)$ & 0 & $(0,0,1,1,0)$ & 0 \\
\hline$(0,1,1,0,1)$ & $(1,1,1,0,1)$ & - & - & - & $(0,0,0,0,0)$ & 0 & $(0,0,1,1,1)$ & - & $(0,0,1,1,1)$ & - \\
\hline$(0,1,0,1,1)$ & $(1,1,0,1,1)$ & - & - & - & $(0,0,0,0,0)$ & 0 & $(0,0,0,0,1)$ & 0 & $(0,0,0,1,1)$ & 0 \\
\hline$(0,0,1,1,1)$ & $(1,0,1,1,1)$ & - & - & - & $(0,0,0,0,0)$ & 0 & - & - & - & - \\
\hline$(1,1,1,1,0)$ & - & - & - & - & $(1,1,1,1,1)$ & - & - & - & - & - \\
\hline$(1,1,1,0,1)$ & - & - & - & - & $(1,1,1,1,1)$ & - & $(1,1,1,1,1)$ & - & $(1,1,1,1,1)$ & - \\
\hline$(1,1,0,1,1)$ & - & - & - & - & $(1,1,1,1,1)$ & - & $(1,1,0,0,1)$ & - & - & - \\
\hline$(1,0,1,1,1)$ & - & - & - & - & $(1,1,1,1,1)$ & - & $(1,1,1,1,1)$ & - & $(1,1,1,1,1)$ & - \\
\hline$(0,1,1,1,1)$ & $(1,1,1,1,1)$ & - & $(1,1,1,1,1)$ & - & $(0,0,0,0,0)$ & 0 & $(0,0,1,1,1)$ & - & $(0,0,1,1,1)$ & - \\
\hline$(1,1,1,1,1)$ & - & - & - & - & $(1,1,1,1,1)$ & - & - & - & - & - \\
\hline
\end{tabular}

Table 2. Votes and collective decisions for digraphs $D_{4}-D_{7}$

\begin{tabular}{|c|c|c|}
\hline $\begin{array}{c}f(D)= \\
D=\end{array}$ & $S A T(D)$ & $P O W(D)$ \\
\hline \hline$D_{\emptyset}$ & $(22,22,22,22,22)$ & $(12,12,12,12,12)$ \\
\hline$D_{1}$ & $(16,28,20,20,20)$ & $(0,24,8,8,8)$ \\
\hline$D_{2}$ & $(20,24,24,20,20)$ & $(8,16,16,8,8)$ \\
\hline$D_{3}$ with $q$ & $(16,24,24,24,16)$ & $(0,16,16,16,0)$ \\
\hline$D_{3}$ with $q^{\prime}, q^{\prime \prime}$ & $(22,22,22,22,22)$ & $(12,12,12,12,12)$ \\
\hline$D_{4}$ with $q, q^{\prime}$ & $(22,22,22,22,22)$ & $(12,12,12,12,12)$ \\
\hline$D_{4}$ with $q^{\prime \prime}$ & $(22,22,22,22,22)$ & $(12,12,12,12,12)$ \\
\hline$D_{5}$ & $(32,16,16,16,16)$ & $(32,0,0,0,0)$ \\
\hline$D_{6}$ & $(24,16,24,16,24)$ & $(16,0,16,0,16)$ \\
\hline$D_{7}$ & $(24,16,24,16,24)$ & $(16,0,16,0,16)$ \\
\hline
\end{tabular}

Table 3. Satisfaction and power in digraphs $D_{0}-D_{7}$ 